\title{
Ram makinelerindeki hava akışının Hesaplamalı Akışkanlar Dinamiği ile modellenmesi
}

\section{Modeling of air flow in stenter machines by Computational Fluid Dynamics}

\author{
Muhammet Tibet Sı̆̆ırcı ${ }^{1}$ (D),Ahmet Erdoğan 2,*iD \\ 1,2 Inönü Üniversitesi, Makine Mühendisliği Bölümü, 44280, Malatya, Türkiye \\ ${ }^{I}$ ILSAN Tekstil Anonim Şirketi, 44900, Malatya, Türkiye
}

\begin{abstract}
Özet
Bu çalışmada, bir tekstil fabrikasında aktif olarak kullanılan bir ram makinesindeki hava akışı Hesaplamalı Akışkanlar Dinamiği (HAD) yöntemi ile modellenmiştir. Sayısal akış simülasyonları ANSYS Fluent paket programında gerçekleştirilmiştir. Akış rejimi daimi ve türbülanslı akıştır. Reynolds Ortalamalı Navier -Stokes (RANS) denklemleri Fluent'te çözdürülmüş, analizlerde Standart k- $\varepsilon$ türbülans modeli seçilmiştir. Akış alanına ait hız verileri görsellerle sunulmuş ve akış verimliliğini etkileyen parametreler karşılaştırılmıştır. Analizler farklı düze geometrileri için gerçekleştirilmiştir. Geometri değişiklikleri düze açıklık oranı (B) ve düze açısı $(\alpha)$ değiştirilerek sağlanmıştır. Mevcut düze geometrisi ile farklı geometrilerin akış alanına ait hız değişkenleri üzerinden karşılaştırma yapılmıştır. Düze açıklık oranının \%20-30 civarında ve düze açısının $0^{\circ}$ (ki bu düzenin yatay konumda olduğu anlamına gelir) olmasının ram makinesinde daha verimli bir akış sağladığ sonucuna varılmıştır.
\end{abstract}

Anahtar kelimeler: Ram makinesi, Düze, Hesaplamalı Akışkanlar Dinamiği, Hava akışı

\section{Giriş}

Tekstil sektörü, Türkiye'de üretim ve ihracat açısından 17.7 milyar dolarlık pay ile tüm sektörler arasında üçüncü sırada yer almaktadır [1]. Enerji ithalatı oranı ise ülkemizde tüm ithalat kalemleri içerisinde $\% 22$ gibi önemli bir paya sahiptir [2]. Tekstil sektöründe tüketilen enerji, sektördeki toplam maliyet içerisinde \%6-14 aralığında bir orana tekabül etmektedir. Tüm sektörler göz önüne alındığında ise tekstil endüstrisinde tüketilen enerji \%7.2 düzeyindedir. Tekstil endüstrisinde önemli miktarda su ve enerji tüketimi gerçekleşmektedir. Enerji kaynaklarına olan ihtiyaç her geçen gün arttığ 1 için tekstil sektöründe tüketilen enerjiyi verimli kullanmak önemli bir konu haline gelmektedir. Tekstil alanında iplik, dokuma, örme, boyama, kurutma ve terbiye gibi birçok üretim süreci bulunmaktadır. Kurutma süreci bu süreçler arasında enerji sarfiyatı en yüksek olan süreçtir [3]. Tüm bu sebepler göz önünde bulundurulduğunda, tekstil sektöründe önemli bir yer tutan kurutma sürecinin iyileştirilmesi adına yapılacak çalışmalar hem enerji tüketimini azaltacak hem de ürün kalitesini

\section{Abstract}

In this study, air flow in a stenter machine, which is actively used in a textile factory, is modelled by the Computational Fluid Dynamics (CFD) method. Numerical simulations were performed in the ANSYS Fluent package program. Flow regime is steady state and turbulent flow. Reynolds Averaging Navier-Stokes (RANS) equations were solved and Standard k- $\varepsilon$ turbulence model was selected in analyses. The velocity data of flow domain were presented with visuals and the parameters affecting the flow efficiency were compared. Numerical flow simulations were carried out for different nozzle geometries. Geometry changes were achieved by changing porosity of nozzle (B) and nozzle angle $(\alpha)$. Comparisons were made between the existing nozzle geometry and the velocity variables of the flow field of different geometries. It has been concluded that the porosity of nozzle is around $20-30 \%$ and the nozzle angle is $0^{\circ}$, which means nozzle is in the horizontal position, providing a more efficient flow in the stenter machine.

Keywords: Stenter machine, Nozzle, Computational Fluid Dynamics, Air flow

arttıracaktır. Tekstil fabrikalarında kumaşın kurutulması işlemi genel olarak iki aşamada gerçekleşmektedir. Mekanik yöntemlerin kullanıldığı ön kurutma aşamasında kumaşın bünyesindeki nemin tamamı kumaştan uzaklaştırılamamaktadır. Isı enerjisinin kullanıldığı ikinci kurutma aşamasında ise nemli ürün üzerindeki doğal nem kaybedilmeden yeterli ölçüde kurutma işlemi gerçekleştirilmektedir [4].

Ram makineleri, 1sı enerjisi vasıtasıyla kumaş terbiye işleminin son aşamasında nemli kumaşı kurutmak için yaygın olarak kullanılır. Ram makineleri; nemli kumaşların, kenarlarından tutturucu elemanlar ile sabitlendiği ve hareketli zincirler vasitasıyla hareket ettirildiği kurutma makineleridir. Nemli kumaşın bu hareketi esnasında kumaşın alt ve üst yüzeylerine her iki taraftan düzeler aracılığıyla sıcak hava jeti çarptırılır ve kumaşın kurutma işlemi gerçekleştirilir. Sicak kurutma havası brülör yardımıyla doğalgaz yakılarak elde edilir (Şekil 1). Daha sonra elde edilen sicak kurutma havası santrifüj fanlar aracılığıyla önce kanala sonra düze deliklerine yönlendirilir. Ram makinelerinde kurutma havasının 1sitılması ve havanın

\footnotetext{
* Sorumlu yazar / Corresponding author, e-posta / e-mail: ahmet.erdogan@ inonu.edu.tr (A. Erdoğan)

Geliș / Recieved: 21.06.2021 Kabul / Accepted: 01.11.2021 Yayımlanma / Published: 14.01.2022

doi: $10.28948 /$ ngmuh. 955437
} 
fanlar vasıtasıyla kumaş üzerine yönlendirilmesi esnasında önemli miktarda enerji tüketimi gerçekleşmektedir. Kurutma süreci, makine içerisindeki kurutma havası akışı ile yakından ilgilidir. Düzeler aracılığıyla uygun akış yapısını elde etmek ram makinelerinin etkinliğini arttıracaktır. Literatürde ram makinelerinin enerji tüketimlerini, kurutma performanslarını ve ram makinesi içerisindeki kurutma havası akışının incelendiği çalışmalar mevcuttur. Juraeva vd. [5], bir ram makinesi içerisindeki düze enjektörlerindeki hava akışını ANSYS CFX yazılımını kullanarak modellemişlerdir. Düze kanal tipinin (düz-eğik), düze kanal yüksekliğinin $(40 \mathrm{~mm}$, $80 \mathrm{~mm}, 160 \mathrm{~mm}$ ) ve düze delik geometrisinin (daire, elips, dörtgen ve beşgen) akışa etkisini incelemişlerdir. Düze üzerindeki her bir enjektörden geçen kütlesel debileri karşılaştırmışlar ve sırasıyla $40 \mathrm{~mm}$ kanal yüksekliğinin, daire delik geometrisinin ve düz kanal tipinin daha iyi sonuçlar verdiğini ortaya koymuşlardır. Llanos vd. [6], bir ram makinesinin kurutma performansını belirlemek için üç farklı HAD simülasyonunu COMSOL yazılımında Standart k- $\varepsilon$ türbülans modelini kullanarak gerçekleştirmişlerdir. Akış hacminde üniform olmayan türbülans yoğunluğunu ve en yüksek hızların enjektörlerin kenar kısımlarında olduğunu gözlemlemişlerdir.

Baxi vd, [7], MATLAB SIMULINK yazılımını kullanarak farklı sektörlerde kullanılabilecek dönel kurutucular için kütle, nem ve 1sı transferi denkliği için matematiksel model geliştirerek bir ram makinesinde modelin uygulanabilirliğini ortaya koymuşlardır. Patel vd. [8], iki farklı ram makinesi ve bantlı konveyör için enerji modelleme temeline dayanan bir kıyaslama çalışması gerçekleştirmişlerdir. Performans göstergeleri olarak özgül enerji tüketimi ve enerji etkinlik katsayısı gibi parametreler belirlemişlerdir. Geliştirdikleri enerji modellemesi vasıtasıyla pamuk ve yün kumaşların kuruma ve taşınma proseslerinde ram makinelerinin ve bantlı konveyörlerin enerji tüketimlerinin $\% 10$ oranında azaltılabileceğini göstermişlerdir. Farklı 1Sı değiştiricisi konfigürasyonları kullanılarak ram makinelerinin egzozunda enerji geri kazanımı için çeşitli metodolojiler de geliştirilmiştir [9]. Ram makinelerinin enerji verimliliğini, kurutma performansını ve 1S1 geri kazanım potansiyelini inceleyen deneysel çalışmalar da mevcuttur [3, 10-13].

$\mathrm{Bu}$ çalışmada, bir tekstil fabrikasında hali hazırda kullanılmakta olan bir ram makinesi içerisindeki hava akışı ANSYS Fluent yazılımı ile modellenmiş ve bu ram makinesi içerisinde kullanılan düzelerin düze açıklığı ve düze açısı gibi bazı geometrik parametrelerinin akış yapısına olan etkileri ortaya konmuştur.

\section{Materyal ve metot}

$\mathrm{Bu}$ çalışmada, akış analizi yapılan katı modelin ölçülendirilmiş şematik görüntüsü iki boyutlu olarak Şekil 2'de verilmiştir. Bir düze dilimi, Şekil 3'de verilen koordinat sistemi göz önüne alındığında z-ekseninde $235 \mathrm{~mm}$ uzunluğa sahiptir. Şekil 3'de “1” ile gösterilen kesitten sicak hava düzeye girer, düze deliklerinden geçerek kumaş ile temas eder ve daha sonra " 2 " ile gösterilen simetrik iki yüzeyden düzeyi terk eder. Analizler üç boyutlu olarak gerçekleştirilmiştir.

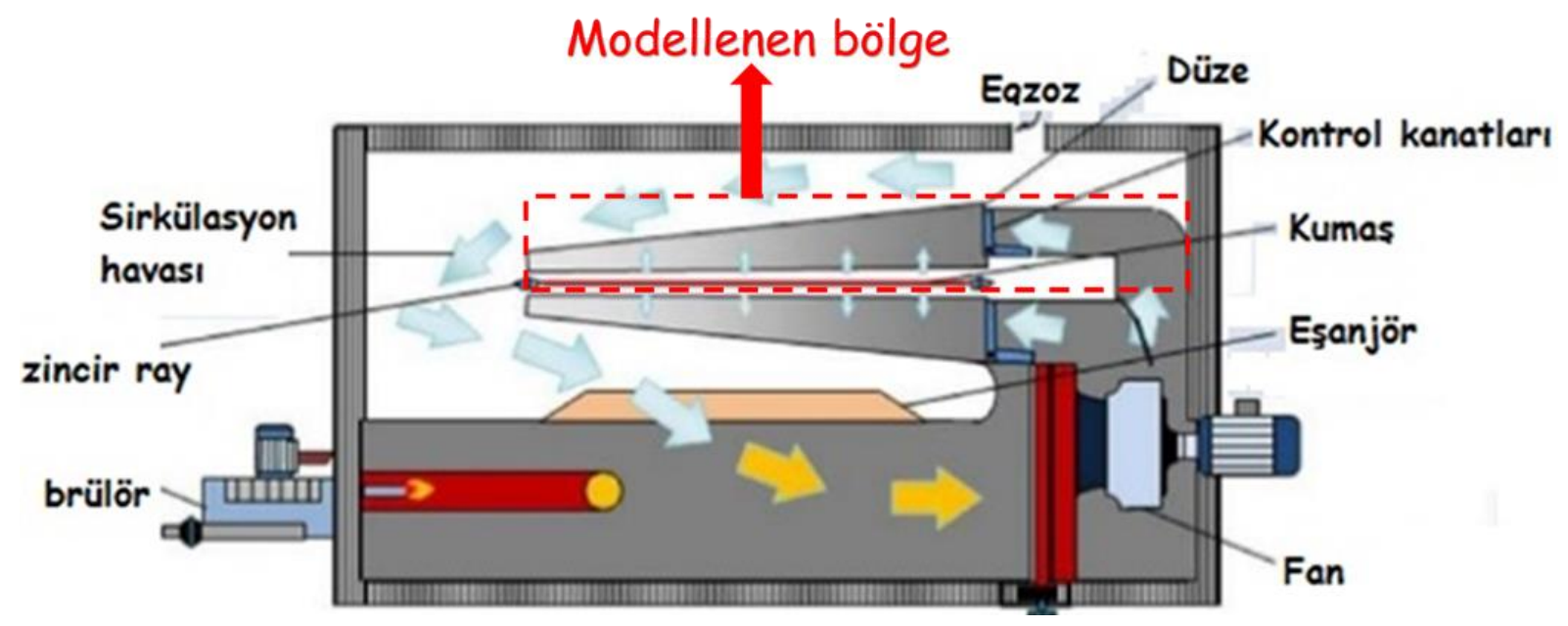

Şekil 1. Doğalgaz brülörlü ram makinesinin şematik gösterimi [14]

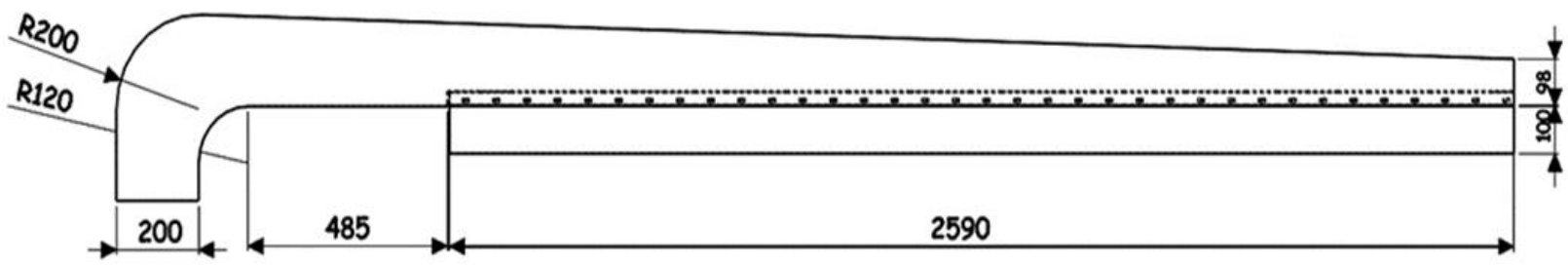

Şekil 2. Ram makinesindeki bir düze diliminin şematik görüntüsü 


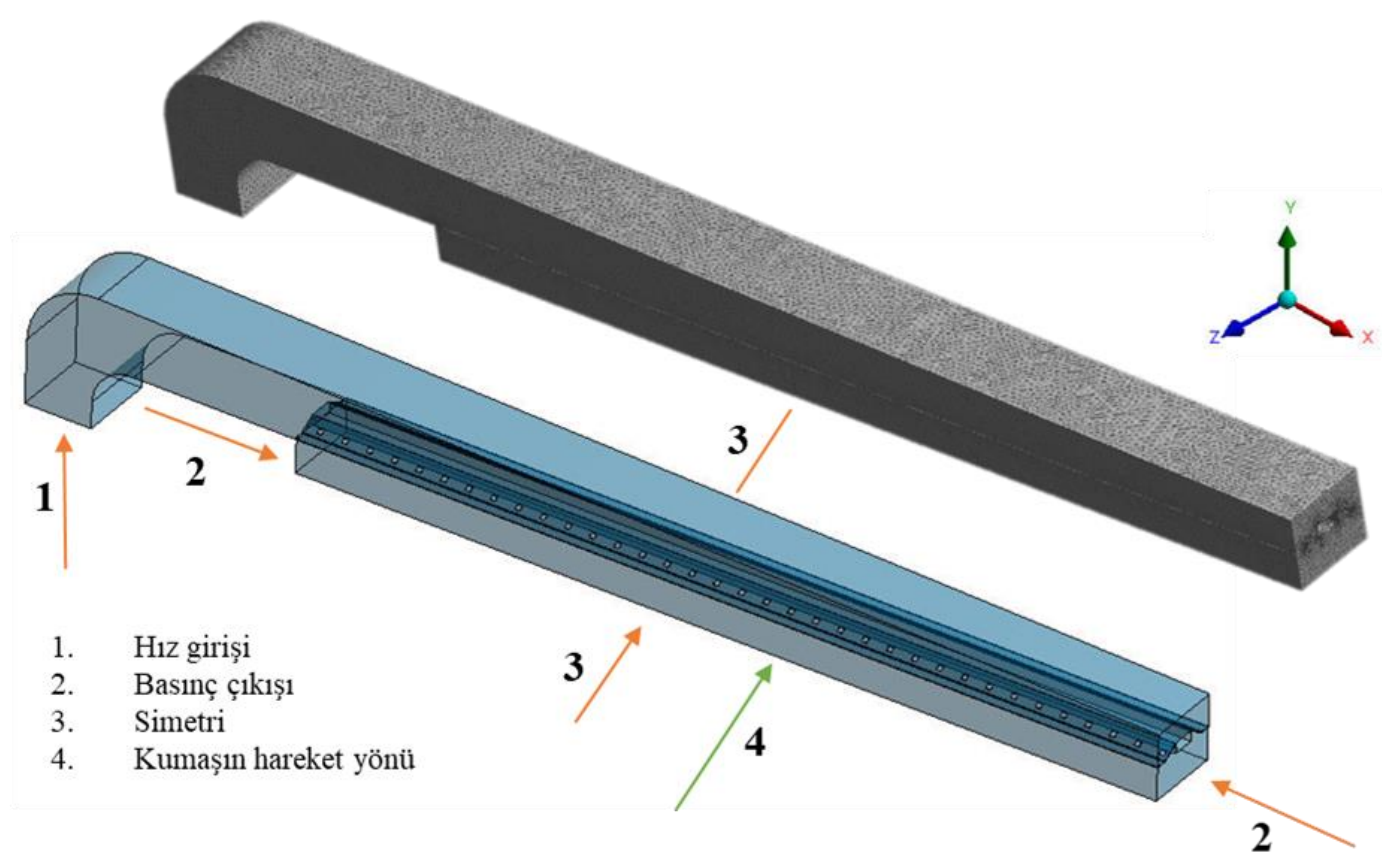

Şekil 3. Sayısal modelin ağ yapısı ve sınır şartları

"1" ile gösterilen kesit (200 mm x 235 mm) sıcak havanın düzeye giriş kesitidir ve modellerde "hız giriși (velocity inlet)" sınır şartı ile tanımlanmıştır. Tüm modellerde hava giriş hızı $5 \mathrm{~m} / \mathrm{s}$ olarak kabul edilmiştir. "2" ile gösterilen simetrik iki yüzey "basınç çıkışı (pressure outlet)" olarak tanımlanmıştır. Çıkış yüzeylerinde, hava atmosferik koşullardadır. Bir ram makinesi, kapasite bakımından farklı sayılarda kabin içermekte olup, bu çalışmada her bir kabin içerisinde 24 adet düze dilimi içeren 10 kabinli bir ram makinesi üzerinde çalışılmıştır. Dolayısıyla ram makinesindeki hava akışını endüstriyel ölçekte modellemek yüksek maliyet ve hesaplama süresi gerektirir. Bu sebeple bu çalışmada, bir dilimdeki hava akışı modellenmiştir. Şekil 2'de, "3" ile gösterilen yüzeylerde "simetri" ve diğer tüm yüzeyler için “duvar (wall)” sınır şartı tanımlanmıştır. Düze delikleri kare geometriye ve $15 \mathrm{~mm}$ x $15 \mathrm{~mm}$ boyutlara sahiptir.

Geometrilerin akış analizleri ANSYS-Fluent programında gerçekleştirilmiştir. Analizlerde daimi akış kabulü yapılmıştır. Sonlu Hacimler Yöntemi ile ayrıklaştırma gerçekleştirilmiş, her bir geometride küçük değişiklikler göstermekle beraber akış hacmi yaklaşık $5 * 10^{6}$ tetrahedral (dört yüzlü) elemana ayrılmıştır. Oluşturulan ağ yapısında en yüksek çarpıklık değeri 0.80 düzeyinde tutulmuştur. Akış hacminde en yüksek eleman boyutu 0.015 $\mathrm{m}$, düze deliklerinin bulunduğu yüzeylerde ise $0.002 \mathrm{~m}$ olarak belirlenmiştir. Modellerde akışkan olarak uygulamadaki gibi hava belirlenmiştir. Havanın yoğunluğu $1.225 \mathrm{~kg} / \mathrm{m}^{3}$ ve viskozitesi $1.7894 * 10^{-5} \mathrm{~kg} / \mathrm{ms}$ 'dir. Akış hacmi değişkenlerini ayrıklaştırmak için SIMPLE algoritmasından yararlanılmıştır. Mekânsal ayrıklaştırma işleminde ikinci mertebeden ileri gidişli şema (second order upwind scheme) seçilmiştir. Her bir analiz için paralel olacak şekilde 8 işlemcide gerçekleştirilmiştir.
$\mathrm{Bu}$ çalışma için düze açısı $(\alpha)$ ve düze açıklık oranı (B) akışa olan etkisinin incelendiği geometrik parametrelerdir. Düze açısı $(\alpha)$ bir düze diliminde düze deliklerinin bulunduğu yüzeyin yatayla yaptığı açıyı temsil etmektedir (Şekil 4). Düze açıklık oranı (B) ise düze deliklerinin bulunduğu eğik yüzey üzerinde delikli alanın toplam yüzey alanına oranını ifade etmektedir. Düze açısı için değerler sirasıyla $\alpha_{1}=0^{\circ}, \alpha_{2}=10^{\circ}, \alpha_{3}=20^{\circ}, \alpha_{4}=30^{\circ}$ olarak belirlenmiştir. Düze açıklık oranı değerleri sırasıyla $\mathrm{B}_{1}=0.05, \mathrm{~B}_{2}=0.1$, $\mathrm{B}_{3}=0.2, \mathrm{~B}_{4}=0.3$ ve $\mathrm{B}_{5}=0.4$ 'tür. Düze açıklık oranı $(\mathrm{B})$ arttıkça hem X-doğrultusundaki delik sayısı artmakta hem de $\mathrm{z}$ doğrultusunda bir sıra daha delik geometrisi eklenmektedir. Bu çalışmada örnek alınan ram makinesi düzesi aktif olarak bir tekstil fabrikasında kullanılan ram makinesinde bulunan düzelerdir. Bu örnek düzeler $\alpha_{4}=30^{\circ}$ açıya ve $\beta_{1}=0.05$ açıklık oranına sahiptir. Sunulan çalışmada, hava akışının sıkıştırılamaz akış olduğu ve $25^{\circ} \mathrm{C}$ sıcaklıkta gerçekleştiği kabul edilmiştir. Bu akış problemi Reynolds Ortalamalı Navier-Stokes (RANS) denklemleri ile tanımlanabilir. Bu denklemlerde, hız ve basınç büyüklükleri zaman ortalamalı ve çalkantı terimleri cinsinden yazılır. Sürekliliği ve momentumun korunumunu ifade eden RANS denklemleri Denklem (1) ve Denklem (2) ile verilmiştir.

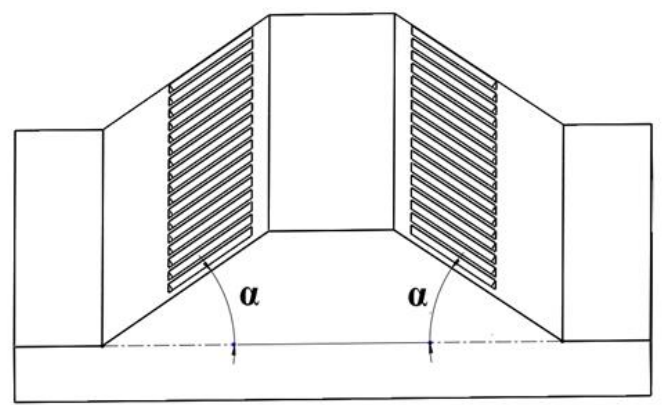

Şekil 4. Düze açısı 


$$
\begin{gathered}
\frac{\partial U_{i}}{\partial x_{i}}=0 \\
\rho U_{j} \frac{\partial U_{i}}{\partial x_{j}}=-\frac{\partial P}{\partial x_{i}}+\frac{\partial}{\partial x_{j}}\left[\mu\left(\frac{\partial U_{i}}{\partial x_{j}}+\frac{\partial U_{j}}{\partial x_{i}}\right)\right] \\
-\frac{\partial}{\partial x_{j}}\left(\rho \overline{u_{\imath}^{\prime} u_{\jmath}^{\prime}}\right)
\end{gathered}
$$

Bu denklemlerde; $i$ ve $j$ alt simgeleri, akışın üç boyutlu olarak gerçekleştiğini dikkate almak için 1,2 ve 3 değerlerini alabilir. $\rho$ akışkanın yoğunluğunu, $U$ kartezyen koordinatlardaki herhangi bir hız bileşenini, $P$ akışkanın statik basıncını, $\mu$ akışkanın dinamik viskozitesini, ve $u^{\prime}$ hızın türbülans çalkantı bileşenini ifade etmektedir. $\rho \overline{u_{\imath}^{\prime} u_{\jmath}^{\prime}}$ ifadesi Reynolds gerilmelerini temsil etmektedir. Reynolds gerilmelerini modelleyebilmek için ilave türbülans modeli denklemlerinin çözümüne ihtiyaç duyulur. Türbülans modeli olarak literatürde ram makinelerinin HAD modellemesi yapılırken uygunluğu ortaya konan [6] Standart $k-\varepsilon$ modeli seçilmiştir. Standart $k$ - $\varepsilon$ türbülans modeli, iki denklemli türbülans modelleri arasında ekonomikliği ve pek çok akış olayında kabul edilebilir doğrulukta sonuç vermesi açısından yaygın olarak kullanılan yarı ampirik bir modeldir. Türbülans kinetik enerjisi $(k)$ ve disipasyon (kayıp) oranı ( $(\varepsilon)$ için yazılan iki adet transport denkleminin çözümü ve türbülans viskozitesinin $\left(\mu_{t}\right)$ hesabını içerir. Kaldırma kuvvetleri etkisi ihmal edildiğinde, bu transport denklemleri $k$ ve $\boldsymbol{\varepsilon}$ için sırası ile Denklem 3 ve Denklem 4'te verilen şekilde yazılabilir [15].

$$
\begin{aligned}
\frac{\partial(\rho k)}{\partial t}+\frac{\partial\left(\rho k u_{i}\right)}{\partial x_{i}} & =\frac{\partial}{\partial x_{j}}\left[\left(\mu+\frac{\mu_{t}}{\sigma_{k}}\right) \frac{\partial k}{\partial x_{j}}\right]+G_{k}-\rho \varepsilon \\
\frac{\partial(\rho \varepsilon)}{\partial t}+\frac{\partial\left(\rho \varepsilon u_{i}\right)}{\partial x_{i}} & =\frac{\partial}{\partial x_{j}}\left[\left(\mu+\frac{\mu_{t}}{\sigma_{\varepsilon}}\right) \frac{\partial \varepsilon}{\partial x_{j}}\right]+C_{1 \varepsilon} \frac{\varepsilon}{k} G_{K} \\
& -C_{2 \varepsilon} \rho \frac{\varepsilon^{2}}{k}
\end{aligned}
$$

Bu denklemlerde yer alan $\mu_{t}$ : türbülans viskozitesi Denklem 5 ile hesaplanmaktadır.

$$
\mu_{t}=\rho C_{\mu} \frac{k^{2}}{\varepsilon}
$$

$\mathrm{Bu}$ denklemlerde; $k$ türbülans kinetik enerjisini, $\varepsilon$ türbülans yitim oranını ifade etmektedir. Denklemlerde bulunan sabitler $\sigma_{k}=1, \sigma_{\varepsilon}=1.3, C_{1 \varepsilon}=1.44, C_{2 \varepsilon}=1.92$ ve $C_{\mu}=0.09$ değerlerini almaktadırlar [15].

\section{Bulgular ve tartışma}

ANSYS Fluent paket programında gerçekleştirilen akış analizleri ile ram makinesindeki hava akışı ile ilgili veriler elde edilmiştir. Sonuçlar irdelenirken özellikle hız alanı ile ilgili veriler göz önünde bulundurulmuştur. Analiz sonuçları farklı kesitlerden alınan akım çizgileri ve hız konturları olarak sunulmuştur. Şekil 5'te, ram makinesinin Şekil 3'te verilen eksen takımı dikkate alındığında xy düzlemi (düze deliklerini içerecek şekilde belirlenen kesit üzerinde) üzerinde belirlenen yüzey üzerindeki akım çizgileri tüm geometrik parametreler için verilmiştir. Şekil 5 incelendiğinde, tüm geometrik parametreler için düze boyunca akışın bu doğrultuda tam olarak homojen dağıllmadığı görülmektedir. Yine tüm geometrik parametrelerde, akışın büyük bölümü düze deliklerinden geçtikten sonra kumaşa çarpmakta ve özellikle düze sonundaki çıkışa doğru (Şekil 3’te düze sonunda "2" ile gösterilmiştir.) yönelmektedir. Akış, düzenin üst kısmında pozitif $\mathrm{x}$-doğrultusunda gerçekleştiği için deliklerden geçtikten sonra akışın büyük bölümünün pozitif $x$ doğrultusuna yöneldiği düşünülmektedir. Şekil 6'da, Şekil 5 'in sunulduğu düzlem üzerinde hız alanına ait konturlar verilmiştir. Şekil 5 ve Şekil 6 birlikte değerlendirildiğinde, düze açıklık oranı (B) düşük olduğunda düze deliklerinden geçen havanın hızı ve dolayısıyla debisi daha yüksek olmaktadır. $\mathrm{B}_{1}=0.05$ değeri için düze deliklerinden geçen hava hızı $20 \mathrm{~m} / \mathrm{s}$ civarına kadar artmaktadır. Bununla birlikte düze açıklık oranının (B) artmasıyla düze deliklerinin hemen alt bölgesinde deliklere yakın kısımlarda daha homojen hız dağı̆lımı oluşmaktadır. Fakat açıklık oranının artışı ile beraber deliklerden geçen hava hızı düşmekte ve havanın bir kısmı en alt yüzeyde bulunan kumaşa temas etmeden, bir kısmı ise kumaşa daha fazla yatay açıyla temas ederek akış bölgesini terk etmektedir. $\mathrm{Bu}$ durumun kurutma performansının düşüşüne yol açabileceği düşünülmektedir. Bunun yanı sıra çok düşük açıklık oranı $(\mathrm{B} 1=0.05)$ değerinde ise kumaşın orta bölgelerinde çok düşük hızlar oluşmaktadır. Şekil 5 ve Şekil 6, düze açısı $(\alpha)$ dikkate alınarak incelenirse, düze açısının $(\alpha)$ artmasıyla deliklerden geçen hava akışının kumaşa daha dar açıyla temas ettiği görülür. Ayrıca düze açısının artmasıyla birlikte yüzeyin orta bölgelerinde akış hızı düşmektedir. $\mathrm{Bu}$ durumların kurutma prosesinin verimini azaltabileceği düşünülmektedir. Şekil 7 ve Şekil 8 'de, y-z düzleminde $x$-doğrultusunda düze deliklerinin başlangıç bölgesi, orta bölgesi ve son bölgesini ifade eden yüzeyler üzerinde akım çizgileri elde edilmiştir. Şekil 7 dikkatli bir şekilde incelenirse, hava akışı düzenin sonuna doğru ilerledikçe deliklerden geçen akış debisinin azaldığ 1 tüm parametreler için akım çizgilerinden de net şekilde anlaşılmaktadır. Düze açıklığı (B) değeri arttıkça düze deliklerinden geçen hava hızı azaldığı için daha kısa mesafede vorteksler oluşmaktadır. Bu durum da hava jeti akışının kumaşa daha düşük yüzey alanında temas etmesine sebep olabilmektedir. Ayrıca düze açıklık oranın artışı deliklerden geçen hava akışının iki yönde vorteks oluşturmasına sebep olmaktadır. Şekil 8'de düze açısının artmasıyla iç kısımlarda kalan deliklerden geçen akışın kumaşla temas alanının azaldığı görülmektedir ki bu durumun kurutma performansına olumsuz etki edeceği düşünülmektedir. Düze açısı arttıkça iç kısımlarda kalan deliklerin kurutma bölgesine yönlendirdiği hava akışı birbirleri ile çarpışmaktadır. Bu durumda akışın sahip olduğu enerjide bir kayıp yaşanabilir. Bu noktada önemli olan kısım deliklerden geçen hava akışının olabildiğince yüksek hızla (kumaşa olumsuz bir etki bırakmayacak kadar yüksek bir hız) kumaşa temas etmesidir. 


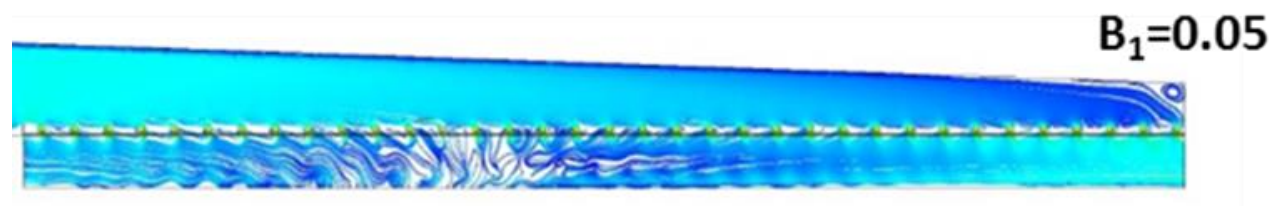

$\mathrm{B}_{2}=0.1$

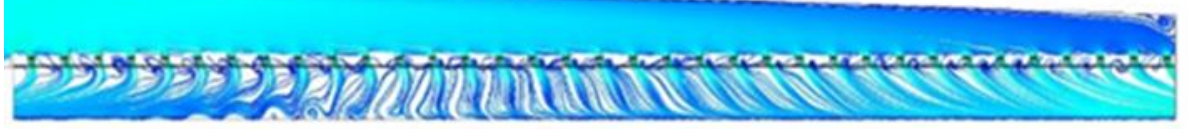
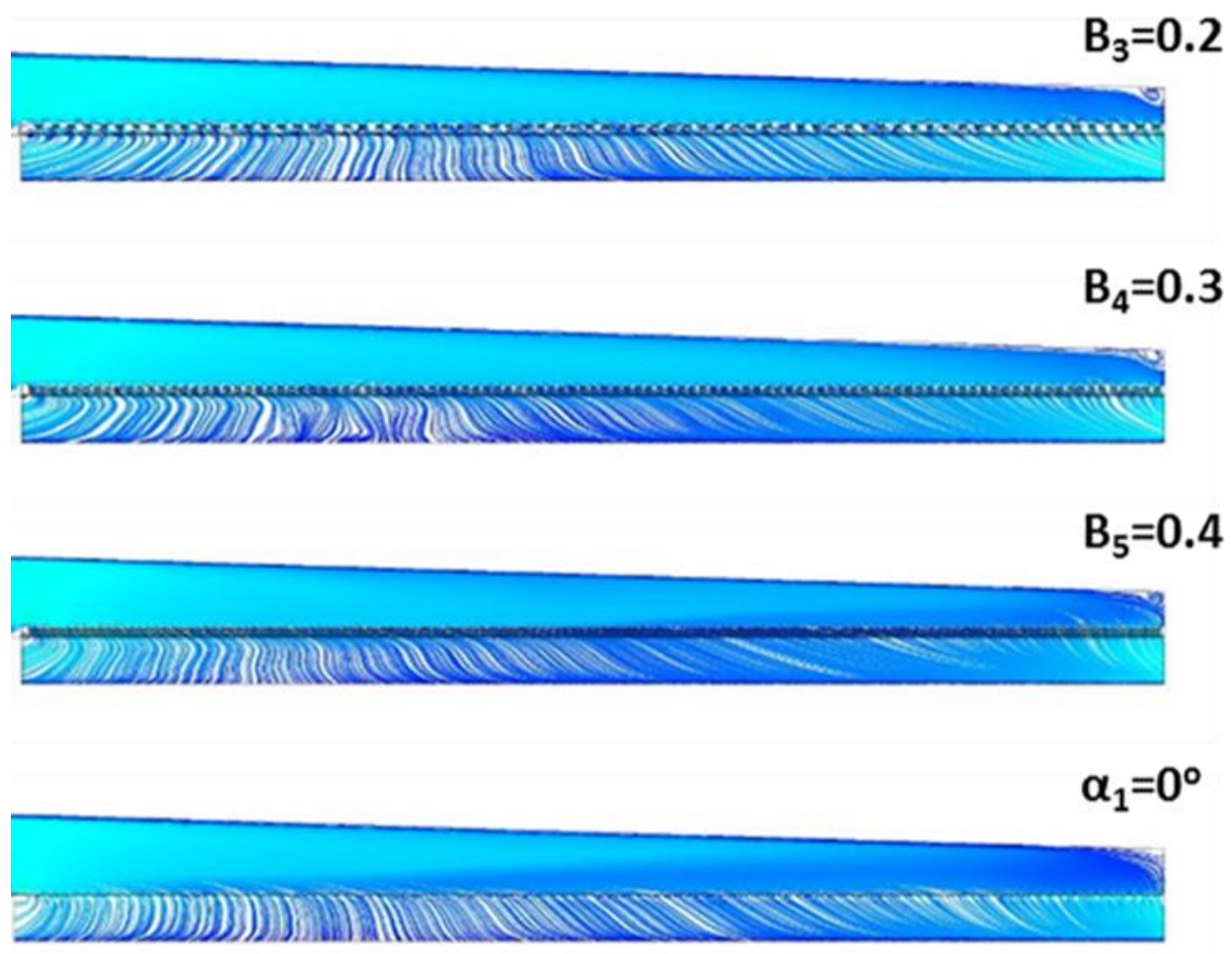

$$
\alpha_{2}=10^{\circ}
$$

Velocity Streamline 1

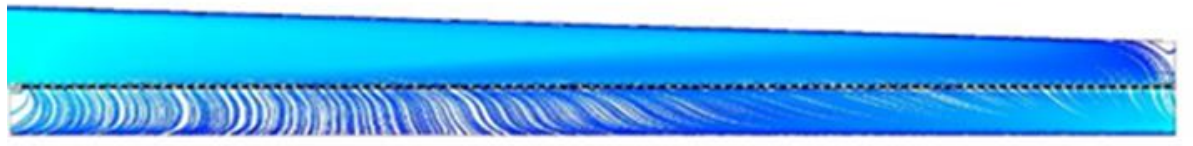

$$
\alpha_{3}=20^{\circ}
$$

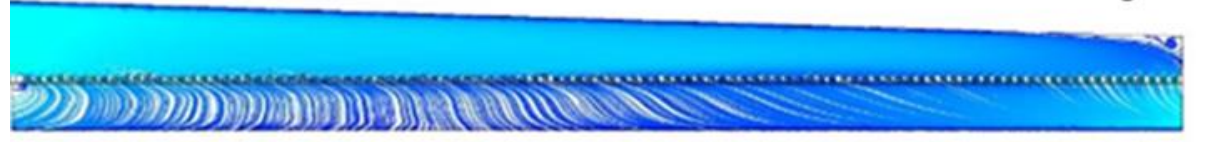

$$
\alpha_{4}=30^{\circ}
$$

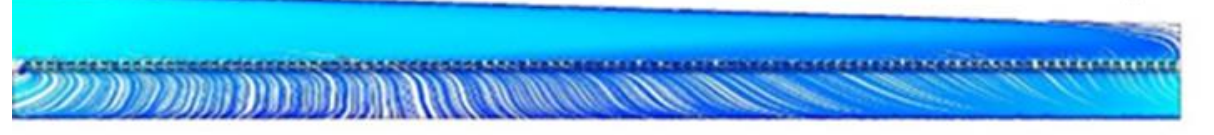

Şekil 5. Farklı açıklık oranları ve farklı düze açıları için düze deliklerinden geçen akışın akım çizgileri 


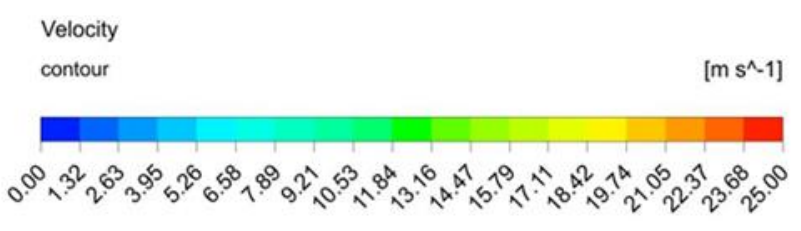

$B_{1}=0.05$

$\mathrm{B}_{2}=0.1$

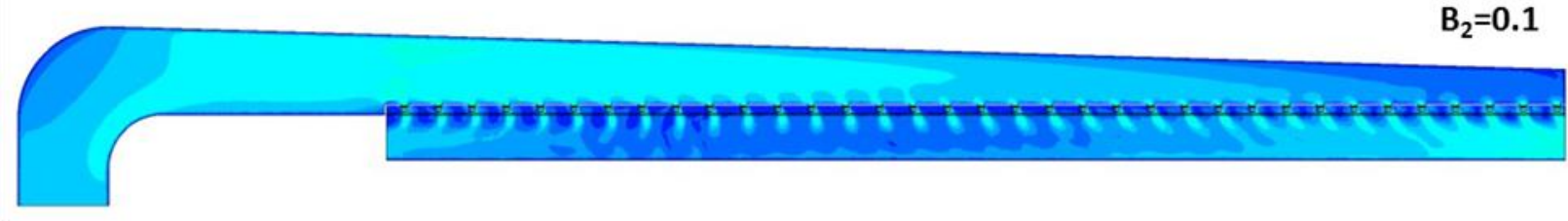

$\mathrm{B}_{3}=0.2$

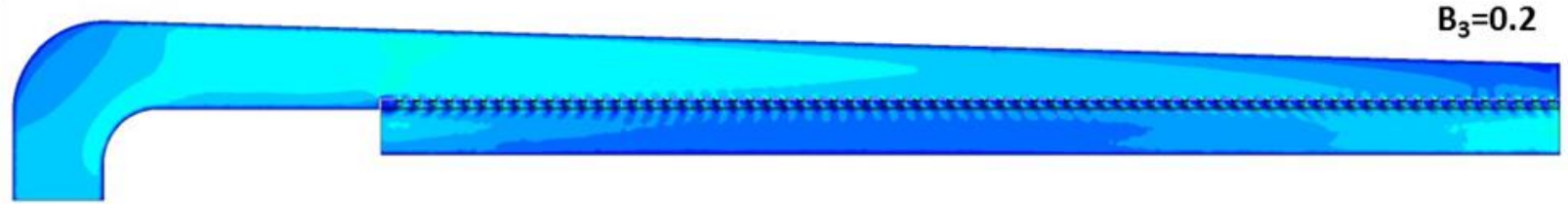

$\mathrm{B}_{4}=0.3$
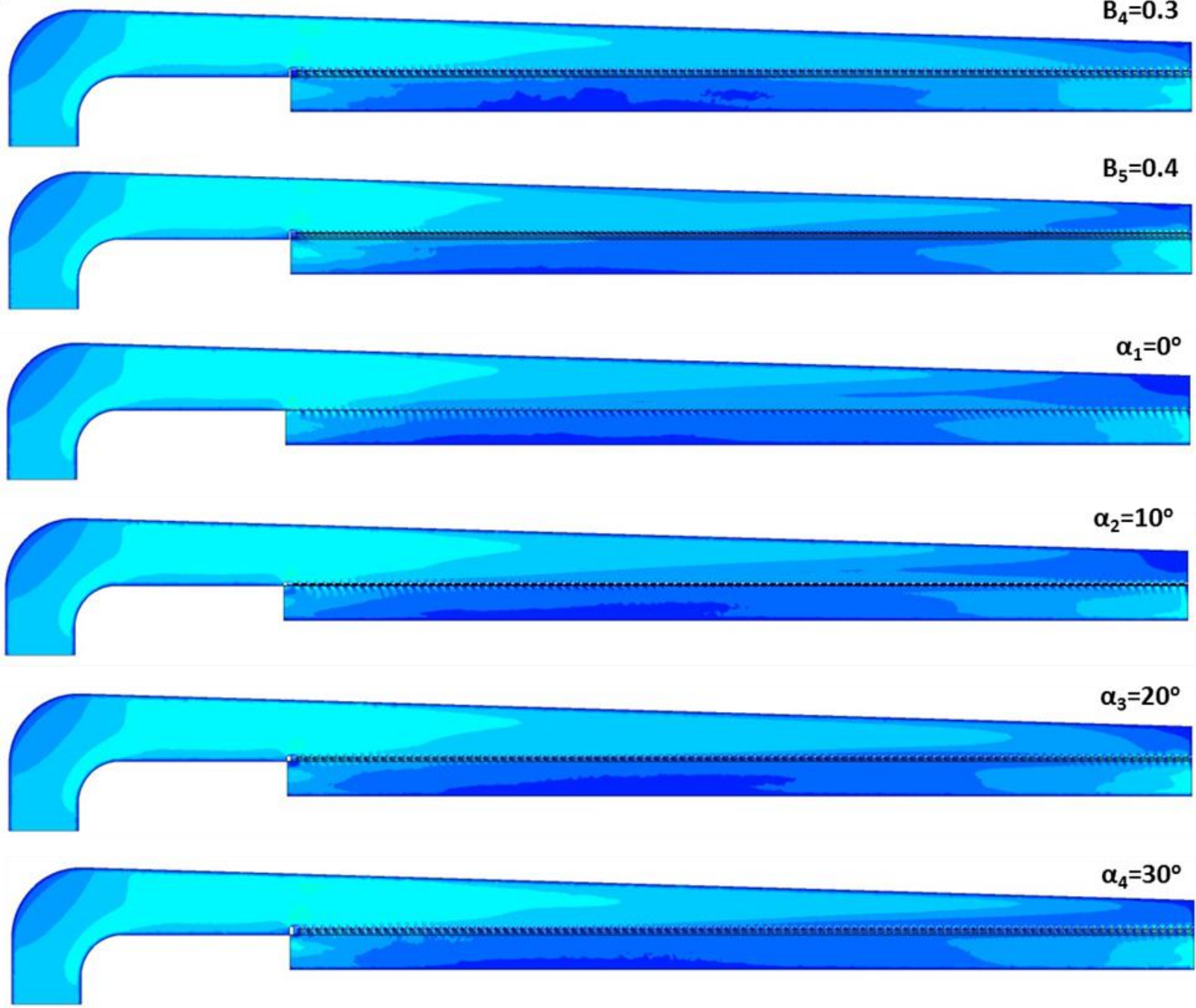

Şekil 6. Farklı açıklık oranları ve farklı düze açıları için düze deliklerinden geçen akışın hız konturları 


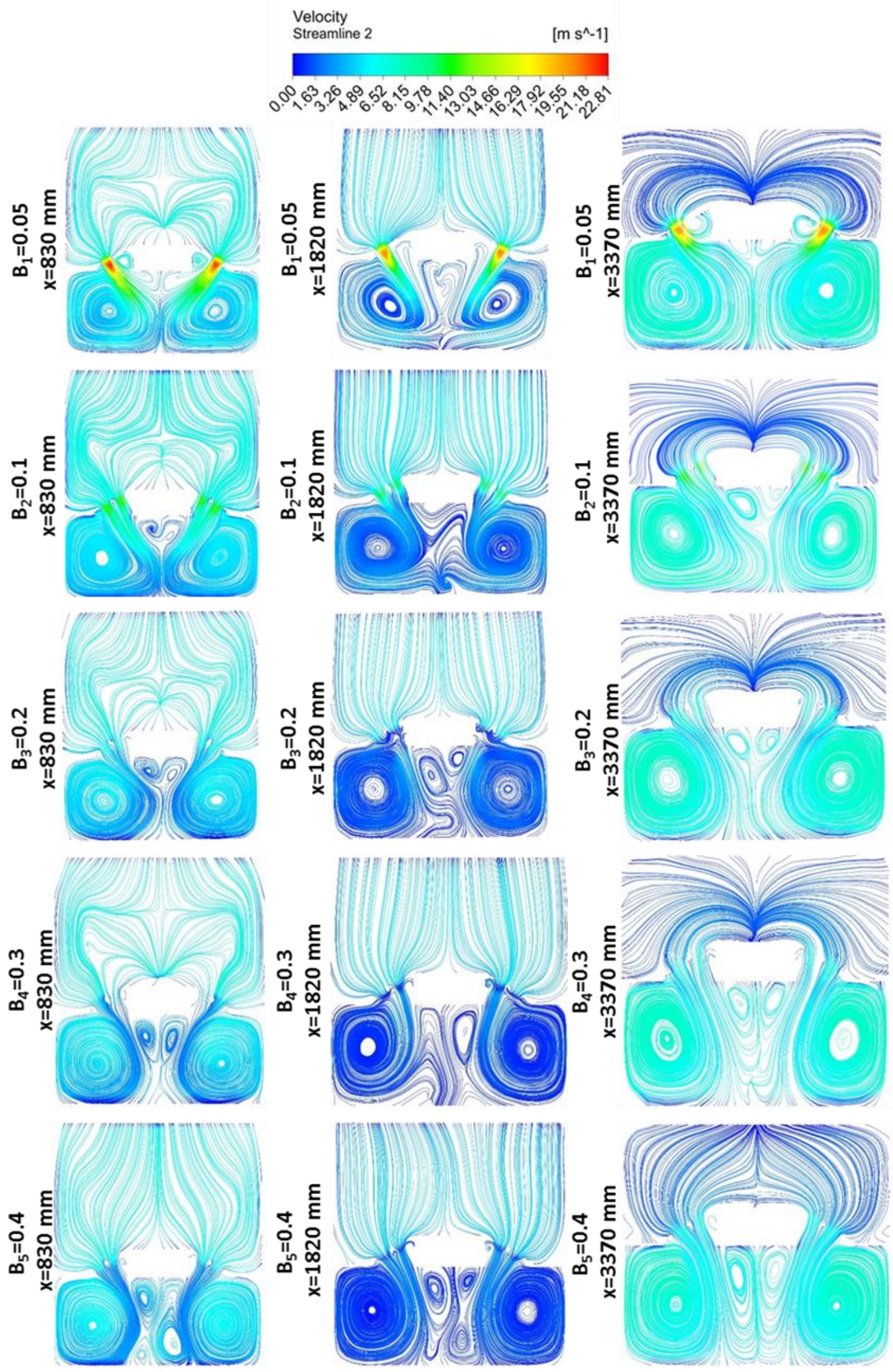

Şekil 7. Farklı açıklık oranları ve farklı y-mesafeleri için düze deliklerinden geçen akışın akım çizgileri 

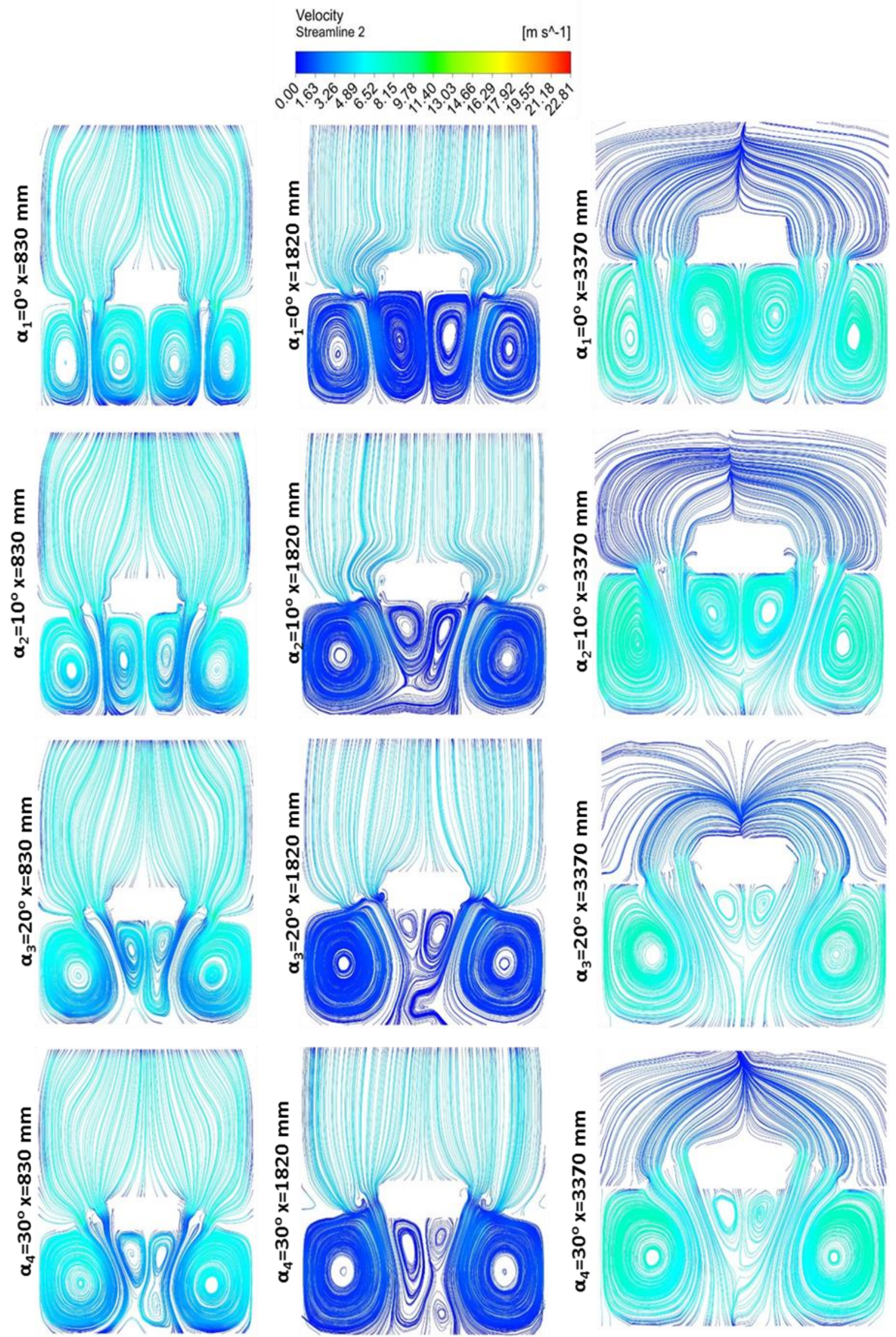

Şekil 8. Farklı düze açıları ve farklı y-mesafeleri için düze deliklerinden geçen akışın akım çizgileri 


\section{Velocity}

Contour 1

$\left[\mathrm{m} \mathrm{s}^{\wedge}-1\right]$

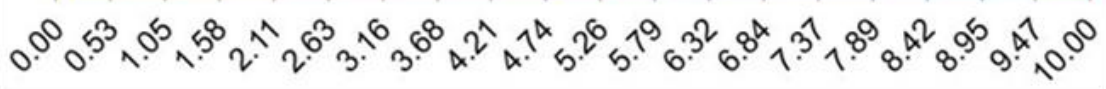

\section{$B_{1}=0.05$}

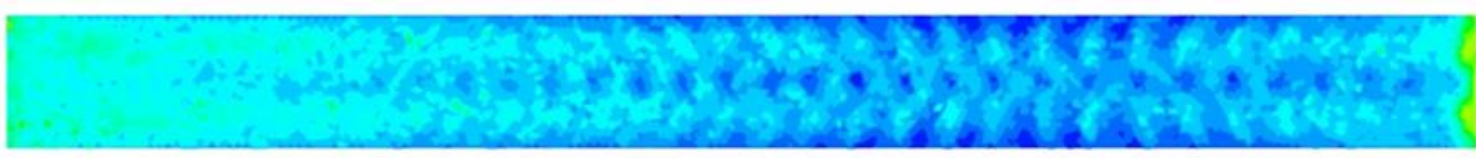

\section{$B_{2}=0.1$}

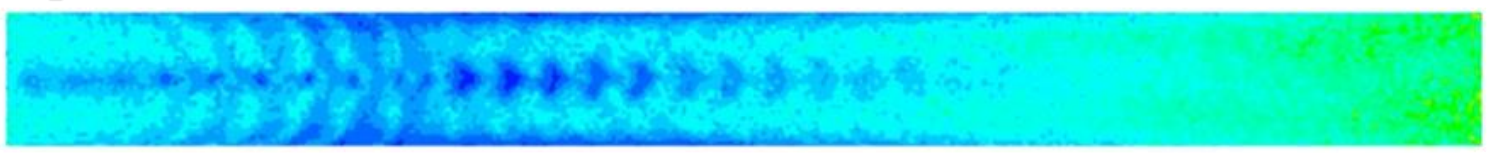

$$
\mathrm{B}_{3}=0.2
$$

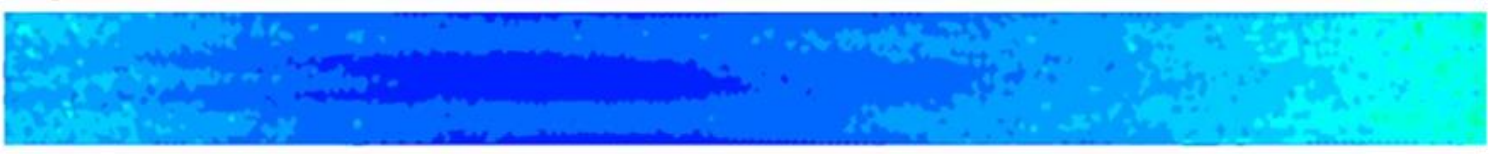

$$
\mathrm{B}_{4}=0.3
$$

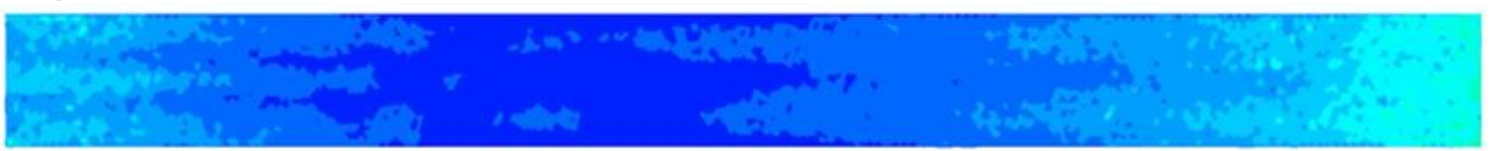

$$
\mathrm{B}_{5}=\mathbf{0 . 4}
$$

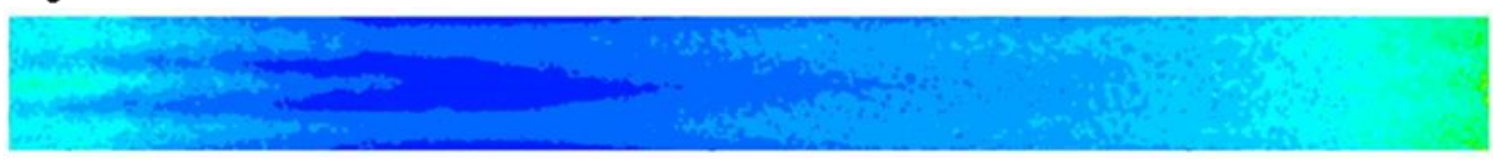

$$
\alpha_{1}=0^{\circ}
$$

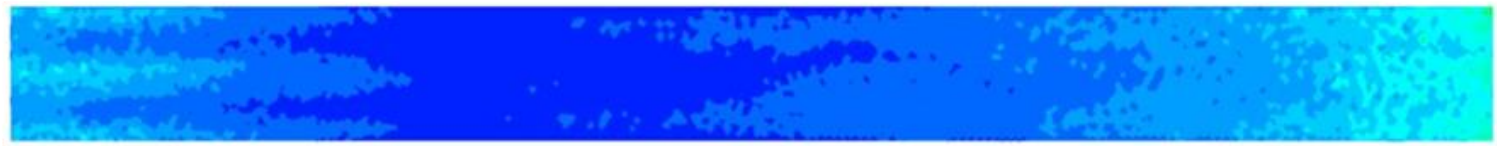

$$
\alpha_{2}=10^{\circ}
$$

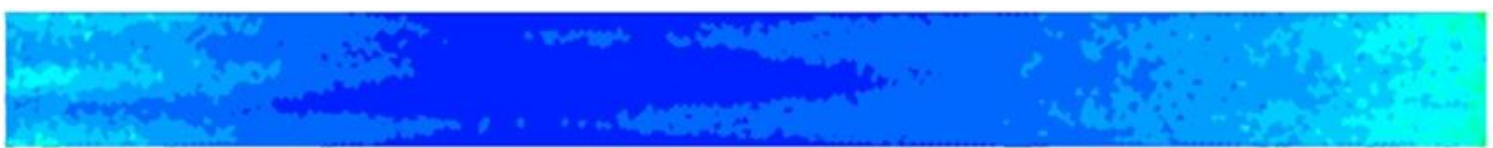

$$
\alpha_{3}=\mathbf{2 0}^{\circ}
$$

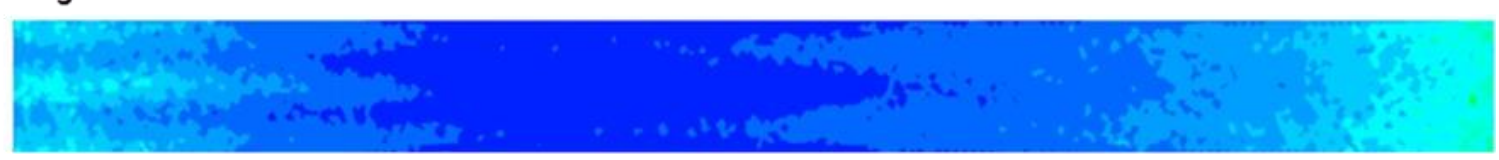

$$
\alpha_{4}=30^{\circ}
$$

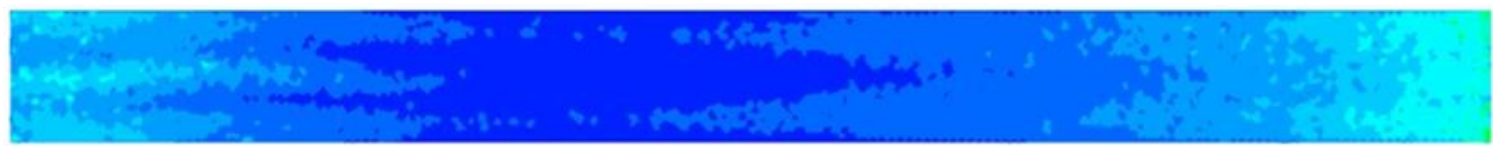

Şekil 9. Farklı açıklık oranları ve farklı düze açıları için kumaşa çarpan hava akışının hız konturları 
Şekil 9'da kumaş üzerindeki hız dağılımını görebilmek için tüm geometrik parametreler için kumaş üzerindeki hız konturları verilmiştir. Tüm geometrik parametrelerde de düze giriş ve çıkış bölgelerine karşılık gelen akış hacimlerinde daha yüksek hava akış hızları oluşmaktadır. $\mathrm{B}_{1}=0.05, \mathrm{~B}_{2}=0.1$ ve $\mathrm{B}_{5}=0.4$ açıklık oranı değerlerinde belirgin bir hız dağılımı farkı oluşmaktadır. $B_{3}=0.2$ ve $\mathrm{B}_{4}=0.3$ açıklık oranı değerlerinde nispeten daha düzgün bir hız dağılımı oluştuğu görülmüştür. Şekil 9'da düze açısı ile ilgili konturlarda, düze açısının kumaş üzerinde belirgin bir fark oluşturmamakla beraber düze açısının düşük olması yani deliklerin bulunduğu yüzeyin daha fazla yatay açıda bulunmasıyla birlikte az da olsa daha homojen bir dağılım oluşturduğu gözlemlenmektedir.

\section{Sonuçlar}

Ram makinelerinde sayısal akış modellemesi gerçekleştirilen bu çalışma ile kumaş kurutma prosesinin iyileştirilmesi adına düze açıklık oranı ve düze açısının akış yapısına etkisi ortaya konmuştur. Özellikle düze deliklerine hava akışını sağlayan kanalın tek bir yönden ve yatay doğrultuda kurutma bölgesine besleme yapması özellikle $\mathrm{x}$ doğrultusunda asimetrik bir hız dağılımına sebep olmaktadır. Bunun yanı sıra ram makinesi içindeki düzelerin açıklık oranının (B) \%20-30 düzeylerinde tutulmasının düze içi hava akış dağılımını iyileştirdiği görülmüştür. Düze açısının $(\alpha)$ ise $0^{\circ}$ 'de (yani düze deliklerinin bulunduğu yüzeyin yatay konumda tutulması durumunda) tutulmasının özellikle düze deliklerinden geçen havanın kumaş yüzeyi ile daha iyi temas halinde olduğu ve kurutma performansını arttıracağ düşünülmektedir.

\section{Teşekkür}

$\mathrm{Bu}$ çalışma, İnönü Üniversitesi Bilimsel Araştırma Projeleri Koordinasyon Birimince " 2425 " kodlu proje kapsamında, aynı zamanda ILSAN Tekstil A.Ş. tarafından desteklenmiştir.

\section{Çıkar çatışması}

Yazarlar çıkar çatışması olmadığını beyan etmektedir.

\section{Benzerlik oranı (iThenticate): $\% 6$}

\section{Kaynaklar}

[1] Türkiye İhracatçılar Meclisi, 2020 Y1lı İhracat Raporları, https://tim.org.tr/tr/ihracat-rakamlari, Erişim 18 Aralık 2020.

[2] Türkiye İstatistik Kurumu, 2020 Y1lı Enerji İthalat Raporlar1, https://data.tuik.gov.tr/Kategori/GetKatego ri? $\mathrm{p}=$ cevre-ve-enerji-103\&dil=1

[3] B. Cinar Gelir and H. Ceylan, The effect of the heat recovery on fuel consumption in the stenter machine,
Thermal Science, 25, 1047-1055, 2021. https://doi.org/10.2298/TSCI190510336C

[4] R. T. Oğulata, F. D. Kadem ve E. Koç, Tekstilde kurutma yöntem ve makinaları, 4. Ulusal Tesisat Mühendisliği Kongresi ve Sergisi, sayfa 803-810, İzmir, Türkiye, 04-07 Kasım 1999.

[5] M. Juraeva, K. J. Ryu, and D. J. Song, Optimum design of the injection duct system of a stenter machine, Journal of Mechanical Science and Technology, 31, 2279-2285, 2017. https://doi.org/10.1007/s12206-0170424-6

[6] W. P. Llanos, M. R. Santos, B. M. Quadri and O. I. Martins, Phenomenological modeling and simulation of a textile stenter, Textile Research Journal, 0, 1-18 2020. https://doi.org/10.1177/0040517520918231

[7] H. Baxi, A. Patel, and J. Barve, Modelling and Simulation of Dryer System. Proceedings of 2015 International Conference on Industrial Instrumentation and Control, pp. 1544-1549, Pune, India, 2015.

[8] N. G. Patel, D. J. Shendageb, M. G. Parikhc, S. K. Basuc and M. H. Badea, Energy model-based benchmarking of the drying process in the stenter machine, Drying Technology an International Journal, 39, 1114-1133 2021. https://doi.org/10.1080/07373937 .2021 .1907401

[9] R. T. Oğulata, Utilization of waste-heat recovery in textile drying. Applied Energy, 79, 41-49 2004. https://doi.org/10.1016/j.apenergy.2003.12.002.

[10] D. Fiaschi, G. Manfrida, L. Russo and L. Talluri, Improvement of waste heat recuperation on an industrial textile dryer: Redesign of heat exchangers network and components. Energy Conversion and Management, 924-940, 150, 2017. https://doi.org/10.1 016/j.enconman.2017.05.053

[11] A.E. Akan ve D. B. Özkan, Ram makinesinde kurutma prosesinin enerji verimliliği analizi, Dicle Üniversitesi Mühendislik Fakültesi Mühendislik Dergisi, 10, 157167, 2019. https://doi.org/10.24012/dumf.434850

[12] A. E. Akan and D. B. Özkan, Experimental examination and theoretical modeling of drying behavior in the ram machine, Drying Technology an International Journal, 38, 1760-1775, 2020. https://doi.org/10.1080/0737393 7.2019. 1662436

[13] A.E. Akan and F. Ünal, Thin-Layer Drying Modeling in the Hot Oil-Heated Stenter, International Journal of Thermophysics, 41, 2020. https://doi.org/10.1007/s10 765-020-02692-X

[14] M. H. Sheshir, Finishing Machines, https://textilelab.blogspot.com/, Erişim 07 Aralık 2020.

[15] Fluent, A. N. S. Y. S. ANSYS fluent theory guide 15.0. ANSYS, Canonsburg, PA, 33, 2013. 